\title{
A spectrofluorimetric study of binary fluorophore-cyclodextrin complexes used as chiral selectors
}

\author{
Francesca D’Anna, ${ }^{*}$ Serena Riela, Michelangelo Gruttadauria, Paolo Lo Meo and Renato Noto* \\ Dipartimento di Chimica Organica 'E. Paternò', Università degli Studi di Palermo, Viale delle Scienze, \\ Parco d'Orleans II, 90128 Palermo, Italy
}

Received 10 December 2004; revised 14 February 2005; accepted 3 March 2005

Available online 31 March 2005

\begin{abstract}
Six binary complexes between three fluorophores (pyrene, xanthone and anthraquinone) and $\beta$-cyclodextrin ( $\beta$-CD) or heptakis(6-amino)-(6-deoxy)- $\beta$-cyclodextrin (am- $\beta$-CD) were tested at two $\mathrm{pH}$ values $(8.0$ and 9.0) as chiral selectors for three $\alpha$-amino acids chosen as model. The conditional constant $\left(\beta_{2 \mathrm{~T}}\right)$ values for ternary complexes (fluorophore-CD-amino acid), determined by means of fluorescence spectroscopy, showed that the binary complexes are suitable receptors for chiral recognition. The effect of $\alpha$-amino acids on stability and stoichiometric ratio of the binary complexes has also been studied. The binary complexes were in most cases stabilized by adding the ternary agent. The trend of stoichiometric ratios found is supported by variations in fluorescence spectra. Those relative to pyrene (Py) show little changes going from binary to ternary complexes, while those recorded in the presence of xanthone (Xan) give the most significant variations underlining a deep reorganization of guest. Anthraquinone (Aq) shows an intermediate behavior.

(C) 2005 Elsevier Ltd. All rights reserved.
\end{abstract}

\section{Introduction}

Chiral recognition is one of the most fundamental aims in stereochemistry. Many authors, such as Ogston, ${ }^{1}$ Cramer, ${ }^{2}$ and more recently Davankov, ${ }^{3}$ have tried to understand the nature of interactions that are needed for a chiral selector to recognize enantiomers. The importance of this topic is also due to the fact that the activity of most biological molecules, indeed in protein recognition phenomena, seems to be due to ability of receptors to interact with amino acid residues in order to give inclusion complexes or supramolecular species. ${ }^{4}$ As amino acids are the main constituents of proteins and, as they show a marked trend to form complexes with a wide variety of molecules, in the last three decades many researchers have attempted to find artificial receptors for these chiral molecules. In fact a better understanding of interactions working in chiral recognition processes can be useful, not only because most therapeutic drugs are developed from chiral amino acid intermediates and are required in an enantiomerically pure form, but also because it can allow the development of new methods of asymmetric synthesis and chromatographic resolution of enantiomers.

Several papers have been published on the synthesis of

Keywords: Cyclodextrins; Chiral recognition; Fluorescence.

* Corresponding authors. Tel.: +39 091596919; fax: +39091596825

(R.N.); e-mail: rnoto@unipa.it chiral macrocyclic compounds and their ability to recognize enantiomers. ${ }^{5}$ On this subject Cram et al. have reported the synthesis of macrocycles having binaphthyl units, which are able to selectively interact with enantiomers of amino acids. ${ }^{6}$ More recently Escuder et al. ${ }^{7}$ have reported the synthesis of molecular receptors able to selectively interact with enantiomers of tyrosine, phenylalanine and tryptophan.

Among semi-natural receptors, cyclodextrins are very important. Thanks to their intrinsically chiral cavity, cyclodextrins have been used in chiral recognition of both L/D amino acids ${ }^{8}$ and small peptide segments. ${ }^{9}$ Very often the chiral recognition of $\alpha$-amino acids results from a ternary complex, formed between a functionalised cyclodextrin, a metal ion and the chiral molecule ${ }^{10}$ in other cases, as recently reported by Liu et al., ${ }^{11}$ the high L-enantioselectivity for leucine is due to the presence of a functional group on the primary rim of cyclodextrin that changes its ability towards molecular and chiral recognition.

Among enantioselective sensors, fluorescent ones are particularly interesting, due to the high sensitivity and selectivity of the detection method. ${ }^{12}$ Until now, little attention has been addressed to the possibility of using fluorescent binary host/guest complexes, formed by cyclodextrin, in studying chiral recognition processes. On this subject, some years ago, Yang and Bohne ${ }^{13}$ reported results concerning the interaction of the complex pyrene/ $\beta$-cyclodextrin with the enantiomers of tryptophan. The 


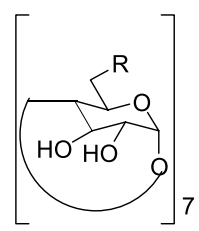

$\mathbf{R}=\mathrm{OH} ; \mathrm{NH}_{2}$

Host structure

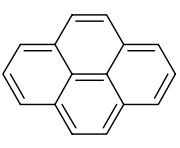

Py

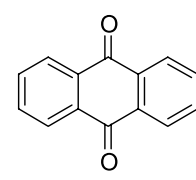

$\mathrm{Aq}$<smiles>O=c1c2ccccc2oc2ccccc12</smiles>

Xan
Guest structure

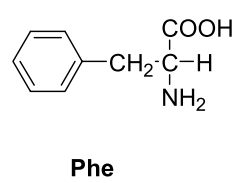

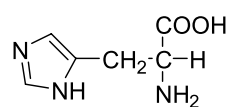

His

Ternary agent structure

Figure 1.

authors found an enantioselectivity ratio of 3.6 for the D-enantiomer. However, they underlined that this high ratio was registered only in the presence of $t-\mathrm{BuOH}(20 \mathrm{mM})$.

More recently we have reported results concerning the study of stability and chiral recognition ability of the binary complex pyrene/heptakis-(6-amino)-(6-deoxy)- $\beta$-cyclodextrin (Py/am- $\beta-C D)^{14}$ and, on that occasion, we pointed out the good chiral recognition ability of the system studied

versus some $\alpha$-amino acids. This ability, in our opinion, was due to the extension of the empty volume of macrocycle cavity that, after inclusion of the fluorescent guest, could be differently occupied by enantiomers of the same amino acid. Recently, in order to identify new fluorescent chiral sensors, we have reported preliminary data concerning the study of stability and stoichiometric ratio of complexes formed by some fluorescent molecules in the presence of $\beta$-cyclodextrin $(\beta-C D)$ and am- $\beta-C D{ }^{15}$

In the present work we have tested the binary complexes formed by pyrene (Py), xanthone (Xan) and anthraquinone (Aq) in the presence of am- $\beta-C D$ and $\beta-C D$, in order to investigate how the symmetry and volume of the cavity of the binary complex influence the chiral recognition. This and the effect of the structure of the ternary agent on the stability of binary complexes were investigated using three different $\alpha$-amino acids: phenylalanine (Phe), methionine (Met) and histidine (His). The study was carried out by spectrofluorimetric titration, in borate buffer at $\mathrm{pH}=8.0$ and 9.0 in order to investigate how the charge of the binary complex influences the interaction with ternary agent. Host, guest and ternary agent structures are depicted in Figure 1.

\section{Results and discussion}

In Tables 1 and 2 the values of stability constants, as a function of $\mathrm{pH}$ value, and stoichiometric ratios for the studied complexes, are reported.

In any case the stoichiometric ratio was determined by Job plot analysis. ${ }^{16}$ Furthermore, in the above Tables the ratios $\beta_{2 \mathrm{~T}} / \beta_{2}$ are also reported, where $\beta_{2}$ is the stability constant of binary complexes and $\beta_{2 \mathrm{~T}}$ is the overall association constant determined in the presence of the ternary agent. These ratios allow the evaluation of the effect due to the ternary agent on the stability of the binary complex.

Table 1. Stability constants and stoichiometric ratios (s.r.) of ternary complexes formed in the presence of $\beta$-CD

\begin{tabular}{|c|c|c|c|c|c|c|c|}
\hline Guest & $\begin{array}{c}\text { S.r. } \\
\text { (Fl/CD) }\end{array}$ & $\begin{array}{c}\text { S.r. } \\
(\mathrm{Fl} / \mathrm{CD} / \mathrm{aa})\end{array}$ & $\begin{array}{c}\text { Ternary } \\
\text { agent }\end{array}$ & $\begin{array}{c}\beta_{2 \mathrm{~T}} / 10^{6}\left(\mathrm{M}^{-2}\right),{ }^{\mathrm{a}} \\
\mathrm{pH}=8.0\end{array}$ & $\begin{array}{c}\beta_{2 \mathrm{~T}} / \beta_{2} \\
\mathrm{pH}=8.0\end{array}$ & $\begin{array}{c}\beta_{2 \mathrm{~T}} / 10^{6}\left(\mathrm{M}^{-2}\right){ }^{\mathrm{a}} \\
\mathrm{pH}=9.0\end{array}$ & $\begin{array}{c}\beta_{2 \mathrm{~T}} / \beta_{2}, \\
\mathrm{pH}=9.0\end{array}$ \\
\hline \multirow[t]{7}{*}{ Py } & $(1: 2)$ & $(1: 2: 2)$ & & $7.5^{b}$ & & $12.0^{\mathrm{b}}$ & \\
\hline & & & L-Phe & 0.9 & 0.1 & 7.4 & 0.6 \\
\hline & & & D-Phe & 3.3 & 0.4 & 7.1 & 0.6 \\
\hline & & & L-Met & 1.8 & 0.2 & 1.2 & 0.1 \\
\hline & & & D-Met & 6.7 & 0.9 & 3.7 & 0.3 \\
\hline & & & L-His & 3.1 & 0.4 & 4.1 & 0.3 \\
\hline & & & $\mathrm{D}-\mathrm{His}$ & 1.2 & 0.2 & 10.7 & 0.9 \\
\hline \multirow[t]{7}{*}{ Xan } & $(1: 1)$ & $(1: 2: 1)$ & & $420^{\mathrm{b}, \mathrm{c}}$ & & $1100^{\mathrm{b}, \mathrm{c}}$ & \\
\hline & & & L-Phe & 5.0 & & 6.1 & \\
\hline & & & D-Phe & 5.4 & & 5.4 & \\
\hline & & & L-Met & 6.2 & & 4.7 & \\
\hline & & & D-Met & 6.6 & & 1.9 & \\
\hline & & & L-His & 7.3 & & 5.4 & \\
\hline & & & D-His & 9.8 & & 6.8 & \\
\hline \multirow[t]{7}{*}{ Aq } & $(1: 2)$ & $(1: 2: 1)$ & & $2.4^{\mathrm{b}}$ & & $10.8^{\mathrm{b}}$ & \\
\hline & & & L-Phe & 2.7 & 1.1 & 5.8 & 0.5 \\
\hline & & & D-Phe & 1.8 & 0.7 & 2.1 & 0.2 \\
\hline & & & L-Met & 1.1 & 0.4 & 6.9 & 0.6 \\
\hline & & & D-Met & 6.2 & 2.6 & 3.8 & 0.3 \\
\hline & & & L-His & 11.1 & 4.6 & 1.3 & 0.1 \\
\hline & & & D-His & 5.2 & 2.2 & 3.1 & 0.3 \\
\hline
\end{tabular}

\footnotetext{
${ }^{a}$ Stability constant values are reproducible within $10 \%$.

${ }^{\mathrm{b}}$ See Ref. 15 .

c As a consequence of the stoichiometric ratio of the binary complex, this value is a $K\left(\mathrm{M}^{-1}\right)$.
} 
Table 2. Stability constants and stoichiometric ratios (s.r.) of ternary complexes formed in the presence of am- $\beta-C D$

\begin{tabular}{|c|c|c|c|c|c|c|c|}
\hline Guest & $\begin{array}{c}\text { S.r. } \\
(\mathrm{Fl} / \mathrm{CD})\end{array}$ & $\begin{array}{c}\text { S.r. } \\
\text { (Fl/CD/aa) }\end{array}$ & $\begin{array}{c}\text { Ternary } \\
\text { agent }\end{array}$ & $\begin{array}{c}\beta_{2 \mathrm{~T}} / 10^{6}\left(\mathrm{M}^{-2}\right){ }^{\mathrm{a}} \\
\mathrm{pH}=8.0\end{array}$ & $\begin{array}{c}\beta_{2 \mathrm{~T}} / \beta_{2} \\
\mathrm{pH}=8.0\end{array}$ & $\begin{array}{c}\beta_{2 \mathrm{~T}} / 10^{6}\left(\mathrm{M}^{-2}\right){ }^{\mathrm{a}} \\
\mathrm{pH}=9.0\end{array}$ & $\begin{array}{c}\beta_{2 \mathrm{~T}} / \beta_{2}, \\
\mathrm{pH}=9.0\end{array}$ \\
\hline \multirow[t]{7}{*}{ Py } & $(1: 2)$ & $(1: 2: 2)$ & & $1.7^{\mathrm{b}}$ & & $4.8^{\mathrm{b}}$ & \\
\hline & & & L-Phe & $8.9^{c}$ & 5.2 & $5.2^{\mathrm{c}}$ & 1.1 \\
\hline & & & D-Phe & $1.2^{\mathrm{c}}$ & 0.7 & $7.6^{\mathrm{c}}$ & 1.6 \\
\hline & & & L-Met & $13.4^{\mathrm{c}}$ & 7.9 & $8.8^{\mathrm{c}}$ & 1.8 \\
\hline & & & D-Met & $2.2^{\mathrm{c}}$ & 1.3 & $1.5^{\mathrm{c}}$ & 0.3 \\
\hline & & & L-His & $7.9^{c}$ & 4.6 & $6.2^{\mathrm{c}}$ & 1.3 \\
\hline & & & D-His & $6.5^{\mathrm{c}}$ & 3.8 & $3.5^{\mathrm{c}}$ & 0.7 \\
\hline \multirow[t]{7}{*}{ Xan } & $(1: 2)$ & $(1: 2: 1)$ & & $3.7^{\mathrm{b}}$ & & $4.5^{\mathrm{b}}$ & \\
\hline & & & L-Phe & 7.1 & 1.9 & 8.9 & 2.0 \\
\hline & & & D-Phe & 7.0 & 1.9 & 7.1 & 1.6 \\
\hline & & & L-Met & 6.8 & 1.8 & 4.9 & 1.1 \\
\hline & & & D-Met & 2.7 & 0.7 & 2.4 & 0.5 \\
\hline & & & $\mathrm{L}-\mathrm{His}$ & 6.1 & 1.6 & 10.9 & 2.4 \\
\hline & & & D-His & 2.4 & 0.6 & 4.5 & 1.0 \\
\hline \multirow[t]{7}{*}{ Aq } & $(1: 2)$ & & & $1.4^{\mathrm{b}}$ & & $2.3^{\mathrm{b}}$ & \\
\hline & & & L-Phe & 1.8 & 1.3 & 2.4 & 1.0 \\
\hline & & & D-Phe & 1.4 & 1.0 & 1.5 & 0.6 \\
\hline & & & L-Met & 1.5 & 1.1 & 1.5 & 0.6 \\
\hline & & & D-Met & 1.3 & 0.9 & 1.8 & 0.8 \\
\hline & & & L-His & 2.1 & 1.5 & 1.2 & 0.5 \\
\hline & & & D-His & 1.8 & 1.3 & 1.6 & 0.7 \\
\hline
\end{tabular}

${ }^{a}$ Stability constant values are reproducible within $10 \%$.

${ }^{\mathrm{b}}$ See Ref. 15 .

${ }^{\mathrm{c}}$ See Ref. 14.

As can be seen from the Tables, in all cases, the complexation of fluorophore to $\beta-\mathrm{CD}$ or am- $\beta-\mathrm{CD}$ can be described by sequential complexation of cyclodextrin molecules (Eqs. 1 and 2): ${ }^{17}$

$\mathrm{S}+\mathrm{CD} \stackrel{K_{1}}{\rightleftharpoons} \mathrm{SCD}$

$\mathrm{SCD}+\mathrm{CD} \stackrel{K_{2}}{\rightleftharpoons} \mathrm{S}(\mathrm{CD})_{2}$

In the presence of a ternary agent, $K_{1}$ and $K_{2}$ are conditional equilibrium constants since they include a term related to the ternary agent concentration. The overall association constant will be given by Eq. 3:

$\beta_{2 \mathrm{~T}}=K_{1} K_{2}=\left[\mathrm{S}(\mathrm{CD})_{2}\right] /\left([\mathrm{S}][\mathrm{CD}]^{2}\right)$

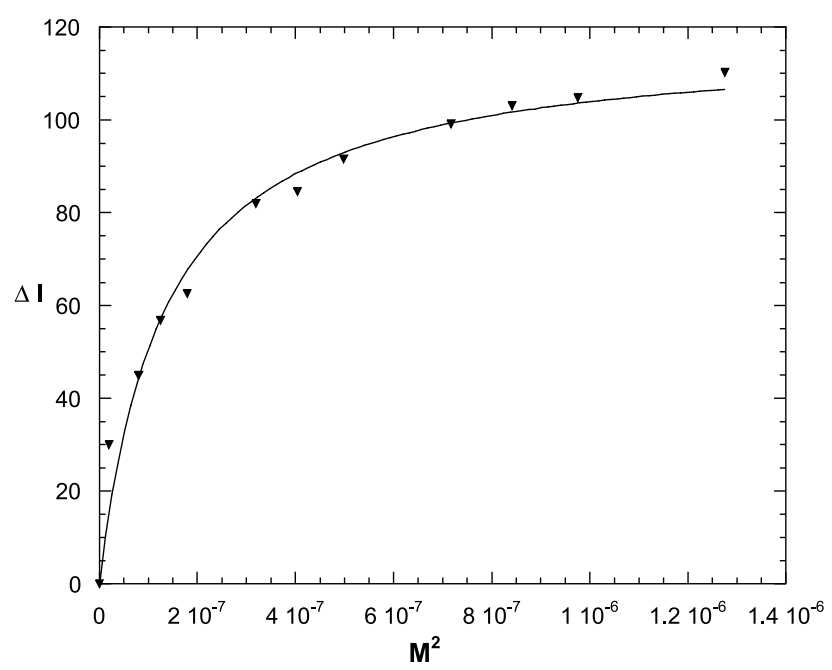

Figure 2. Curve fitting analysis of fluorescence spectral titration of Xan with $\beta-\mathrm{CD}$, in the presence of $\mathrm{L}-\mathrm{Met}$, in borate buffer solution at $\mathrm{pH}=8.0$.
If $[\mathrm{CD}] \gg[\mathrm{S}]$ the change in the fluorescence intensity as function of $\mathrm{CD}$ concentration will be given by Eq. 4:

$\Delta I=\left(\Delta \alpha \beta_{2 \mathrm{~T}} S_{\mathrm{t}}\left[\mathrm{CD}_{0}\right]^{2}\right) /\left(1+\beta_{2 \mathrm{~T}}\left[\mathrm{CD}_{0}\right]^{2}\right)$

where $\Delta \alpha$ is the difference of emission quantum yields of free and complexed substrate, $S_{\mathrm{t}}$ and $\left[\mathrm{CD}_{0}\right]$ are the total concentration of substrate and cyclodextrin, respectively.

All guests used in this work have shown a good sensitivity to microenvironmental changes. In fact, in all cases considered, we detected significant changes of fluorescent intensity ( $\Delta I$ ranging from -110 up to 80 a.u.) when the $C D$ concentration increased and these changes were higher in the presence of ternary agent (Fig. 2). In particular Py and Aq showed a higher fluorescent intensity when they were included in CD cavity, than Xan. This latter result perfectly agrees with the reported dependence on medium polarity of emission spectrum of Xan. ${ }^{18}$ Indeed, a decrease in the fluorescence intensity was observed by addition of a solvent less polar than water, such as 1,4-dioxane, to an aqueous solution of Xan.

The analyzed properties of ternary complexes are obviously influenced by the structure of the three partners, that is, fluorophore, cyclodextrin, amino acid. For example, the $\mathrm{pH}$ differently affects the two cyclodextrins according to the behavior of hydroxyl or amino groups as a function of the medium acidity. Consequently, the $\mathrm{pH}$ variation can be important in determining stability, stoichiometric ratio and chiral recognition ability of the complex.

\subsection{Stoichiometric ratio}

The symmetry and size of the fluorophore used plays an important role in determining the binary complex stoichiometric ratio. In fact, the most symmetric guests, $\mathbf{P y}$ and $\mathbf{A q}$, form binary complexes having a (1:2) (fluorophore/CD) 


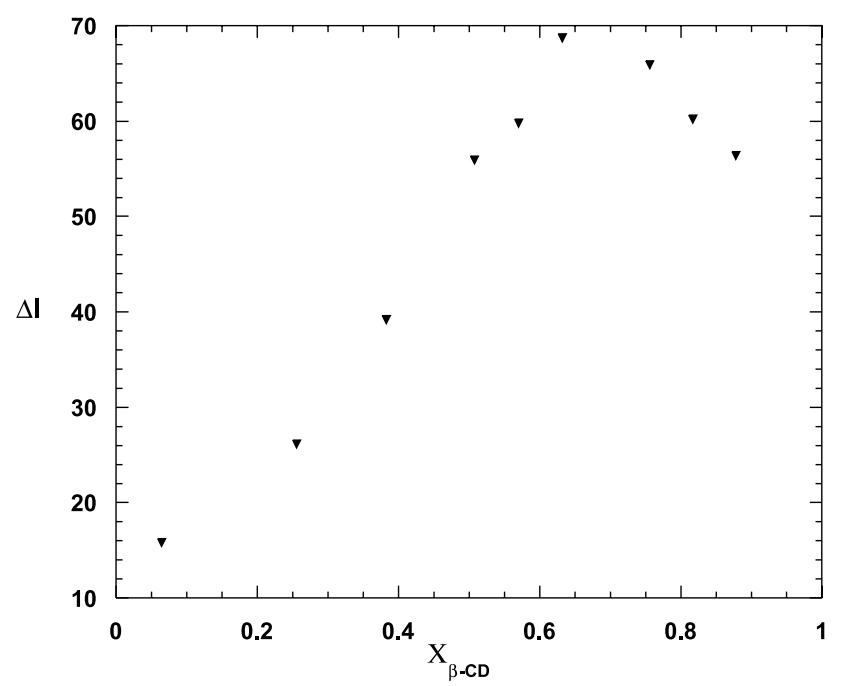

Figure 3. Job plot of the ternary complex Xan/ $\beta-\mathrm{CD} / \mathrm{L}-\mathbf{P h e}$ in borate buffer solution at $\mathrm{pH}=8.0$.

stoichiometric ratio, whereas Xan forms (1:1) and $(1: 2)$ (fluorophore/CD) binary complexes with $\beta-\mathrm{CD}$ and am- $\beta$ $\mathrm{CD}$, respectively. As can be seen from Tables 1 and 2 the addition of ternary agent does not change the binary complex stoichiometric ratio, only in the case of Xan/ $\beta-C D$ was a change in the stoichiometric ratio observed (Fig. 3).

However, data obtained from Job plot analysis show that the six binary complexes have different properties of inclusion towards the amino acids. Thus, Py forms a ternary complex having a (1:2:2) (Py/CD/amino acid) stoichiometric ratio, where each cyclodextrin cavity is equally occupied by a chiral molecule. The Aq guest, smaller than Py, probably gives a more flexible binary complex. As a consequence of this, the ternary agent partially displaces Aq, so, in the presence of $\beta$-CD, a ternary complex having a (1:2:1) (Aq/ $\beta$-CD/amino acid) stoichiometric ratio was observed. In this complex, the chiral molecule can occupy only the cavity having a major empty volume. A particular behavior has been found in the presence of the Aq/am- $\beta$-CD complex; in fact, in this case, the Job plot analysis did not give a curvilinear plot. Probably, more ternary complexes, having different stoichiometric ratios $[(1: 2: 1)$ and $(1: 2: 2)$ (fluorophore/am- $\beta$-CD/amino acid)] were present.

Some different results were found for Xan. The asymmetric arrangement of the guest molecule with respect to cyclodextrin cavity ${ }^{15}$ seems to be responsible for the lower ternary complex symmetry. It is noteworthy that in the presence of the binary complex $\mathbf{X a n} / \beta-C D$ the addition of the amino acid leads to a reorganization in the host-guest interactions and a change in the guest/host stoichiometric ratio [from (1:1) in the binary complex to $(1: 2)$ in the ternary complex]. Probably, in the presence of the amino acid, the guest molecule is partially moved out of the $\beta-C D$ cavity and interacts much more with solvent molecules. Thus in order to reduce such an unfavorable interaction, a second $\beta-\mathrm{CD}$ molecule encloses the protruding part of the guest. This result is different from that previously reported by Bohne et al. ${ }^{20}$ They found no change in stoichiometric ratio of the binary complex $\mathbf{X a n} / \beta-\mathrm{CD}$ on the addition of aliphatic alcohols.

The trend of stoichiometric ratios found is supported by variations in fluorescence spectra. Those relative to $\mathbf{P y}$ show little change going from binary to ternary complexes, while those recorded in the presence of Xan give the most significant variations underlining a deep reorganization of the guest. Aq shows an intermediate behavior.

\subsection{Host structure}

Data reported in Tables 1 and 2 show that host structure is one among the factors that affect the ternary complexes stability. In fact, it often has a scarce relevance in determining the difference in stability between two complexes. In some cases ( $\mathrm{six}$ ), the complexes formed by am- $\beta$ $\mathrm{CD}$ are more stable (from 10 up to 2 times) than complexes formed by $\beta-C D$, and in some other cases (twelve) the former are less stable (from 11 up to 2 times). Finally, for eighteen ternary complexes a scarce influence of host structure was observed. However, in order to evaluate the effect of the ternary agent on the stability of binary complexes, it is suitable to consider the $\beta_{2 \mathrm{~T}} / \beta_{2}$ ratio rather than the $\beta_{2 \mathrm{~T}}$ values.

As can be seen from the Tables, in the presence of am- $\beta$ $\mathrm{CD}$, in most cases, the addition of a ternary agent stabilizes the binary complex. In general this stabilization is higher at $\mathrm{pH}=8.0$ than at $\mathrm{pH}=9.0$. In order to explain these data, it is possible to consider the different charge of the host, when the $\mathrm{pH}$ increases, or, alternatively, the different interactions between ternary agent and primary rim of the host at two different $\mathrm{pH}$ values.

At $\mathrm{pH}=8.0$, the am- $\beta-\mathrm{CD}$ is in its charged form; it interacts better with water molecules and consequently, the effect of addition of the amino acid is greater, as water molecules are displaced from the empty volume of the cyclodextrin cavity. On the other hand, as previously reported, ${ }^{14}$ data obtained seem to indicate that electrostatic interactions present, at $\mathrm{pH}=8.0$, between the ammonium groups of am- $\beta-\mathrm{CD}$ and the carboxylate group of the amino acid, are more efficient than the hydrogen bonds that stabilize the system at $\mathrm{pH}=9.0$.

A more diversified behavior was registered in the presence of $\beta$-CD. In particular for $A q / \beta-C D$, in most cases, the binary complex was stabilized by adding the ternary agent and the degree of stabilization is higher at $\mathrm{pH}=8.0$ than at $\mathrm{pH}=9.0$. This result, apparently anomalous, can be explained considering the effect of base concentration. In fact, as previously reported, ${ }^{15}$ a higher base concentration, on going from $\mathrm{pH}=8.0$ to $\mathrm{pH}=9.0$, could break the network of hydrogen bonds on the secondary rim, allowing the best substrate-cyclodextrin complex fit; as a consequence, the more stable complex will be less affected by adding the ternary agent. For $\mathbf{P y} / \beta-\mathrm{CD}$ complex, a destabilization of the binary complex was always observed. The lack of $\beta_{2 \mathrm{~T}} / \beta_{2}$ ratio values for $\mathbf{X a n} / \beta-\mathrm{CD}$ complex does not allow a comparison between the two Xan/CD systems. 


\subsection{Guest structure}

The studied guests have different polarity and hydrophobicity. In particular Py is hydrophobic and apolar, while Aq and Xan are moderately hydrophilic but apolar and polar, respectively.

Data reported in Table 2 seem to indicate that, in the presence of am- $\beta-C D$, the degree of stabilization is determined by guest hydrophobicity. In fact, $\beta_{2 \mathrm{~T}} / \beta_{2}$ ratios are higher in the presence of the Py/am- $\beta$-CD complex, while less significant differences were obtained between Aq/am- $\beta$-CD and $\mathbf{X a n} / \mathrm{am}-\beta-\mathrm{CD}$ complexes, underlining that guest symmetry plays a secondary role.

Instead, in the presence of $\beta$-CD (Table 1), it is not easy to identify the guest parameter responsible for $\beta_{2 \mathrm{~T}}$ values.

\subsection{Ternary agent structure}

The ternary agents studied have different side chains: apolar for Phe, polarizable for Met, polar and negatively (at $\mathrm{pH}$ values investigated) charged for His. However, data reported in the Tables show that, in the presence of both $\mathrm{am}-\beta-\mathrm{CD}$ and $\beta-\mathrm{CD}$ and apart from the guest used, there is not a simple correlation between complex stability and side chain structure of the ternary agent. Despite this, and in order to evaluate how the ternary agent nature affects the ternary complex stability, it could be interesting to compare these data with those previously reported for similar systems.

Previously, Bohne et al. $^{20}$ found that the $\mathbf{X a n} / \beta-\mathrm{CD}$ complex, having a (1:1) stoichiometric ratio, was destabilized by adding the structural isomers of butanol. Differently in the present work, the addition of amino acid molecules induces a variation in the stoichiometric ratio [from $(1: 1)$ to $(1: 2)]$ of $\mathbf{X a n} / \beta-C D$ complex. For Xan $/ \mathrm{am}-\beta-\mathrm{CD}$ complex the inclusion of amino acids molecules does not change the stoichiometric ratio. Furthermore, in most cases, there is a stabilization of the binary complex and also when the ternary complex is less stable than the binary complex (D-Met at $\mathrm{pH}=8.0$ and 9.0, $\mathrm{D}-\mathrm{His}$ at $\mathrm{pH}=8.0$ ), the entity of destabilization is lower than that recorded in the presence of alcohols. Probably this is a consequence of the different nature of ternary agents used. In fact, the charged amino acid molecules are more solvated and less deeply included, reducing their destabilizing effect.

The stability of ternary complexes formed by the $\mathbf{P y} / \beta-\mathrm{CD}$ complex, in the presence of alcohols ${ }^{21}$ and amino acids ${ }^{19}$ has been previously reported. Data obtained in the present work, in buffer solution, show that the stability of the complexes is higher than that previously reported, underlining the importance of the solvent medium. Probably, in our case, the higher ion concentration induces the apolar Py to interact more strongly with the cyclodextrin cavity and, consequently, to feel more strong by the effect of ternary agent presence.

It is noteworthy that the stabilities of complexes, determined by us, are comparable with those previously reported in the presence of alcohols that had been considered more efficient ternary agents than amino acids. ${ }^{19}$ Furthermore, differently from that previously reported by Bohne et al., ${ }^{19}$ also His, having a charged side chain, is able to interact with the binary complex giving rise, in most cases, to its stabilization.

\subsection{Chiral discrimination}

In Table 3 the enantioselectivity ratios for the different binary complexes as a function of $\mathrm{pH}$ values are reported.

As can be seen from the Table, the binary complexes are able to differentiate amino acids not only for their different size and shape, but also for their chirality. The highest L-enantioselectivity is 7.4 , for Phe with $\mathbf{P y} / \mathrm{am}-\beta-\mathrm{CD}$, while the highest D-enantioselectivity is 5.6, for Met with Aq $/ \beta-C D$.

Some interesting observations can be inferred from data in Table 3. The binary complexes fluorophore/am- $\beta-C D$ generally show L-enantioselectivity, the D-enantioselectivity of $\mathbf{A q} / \mathrm{am}-\beta-\mathrm{CD}$ complex at $\mathrm{pH}=9.0$ could be a consequence of the fact that for this complex at least two different ternary complexes are present. The behavior of binary complexes of $\beta-C D$ is more variegated. In fact, for $\mathbf{P y} / \beta-C D$ and $\mathbf{X a n} / \beta-C D$ the D-enantioselectivity prevails, while $\mathbf{A q} /$ $\beta$-CD shows L-enantioselectivity.

Looking at guest structure, in the presence of both $\beta-\mathrm{CD}$ and am- $\beta-C D$, enantioselectivity ratios decrease going from $\mathbf{P y}$

Table 3. Enantioselectivity ratios (E.r.) determined in the presence of $\beta-C D$ and am- $\beta-C D$

\begin{tabular}{|c|c|c|c|c|c|}
\hline Guest & $\begin{array}{c}\text { Ternary } \\
\text { agent }\end{array}$ & $\begin{array}{c}\text { E.r. }(\beta-C D), \\
\mathrm{pH}=8.0\end{array}$ & $\begin{array}{c}\text { E.r. }(\beta-C D), \\
\mathrm{pH}=9.0\end{array}$ & $\begin{array}{c}\text { E.r. }(\mathrm{am}-\beta-\mathrm{CD}), \\
\mathrm{pH}=8.0\end{array}$ & $\begin{array}{c}\text { E.r. }(\mathrm{am}-\beta-\mathrm{CD}), \\
\mathrm{pH}=9.0\end{array}$ \\
\hline \multicolumn{6}{|l|}{ Py } \\
\hline & Phe & $3.7\left(\mathrm{D}>_{\mathrm{L}}\right)$ & 1.0 & $7.4(\mathrm{~L}>\mathrm{D})^{\mathrm{a}}$ & $1.5\left(\mathrm{D}>_{\mathrm{L}}\right)^{\mathrm{a}}$ \\
\hline & Met & $3.7(\mathrm{D}>\mathrm{L})$ & $3.1(\mathrm{D}>\mathrm{L})$ & $6.1(\mathrm{~L}>\mathrm{D})^{\mathrm{a}}$ & $5.9(\mathrm{~L}>\mathrm{D})^{\mathrm{a}}$ \\
\hline & His & $2.6(\mathrm{~L}>\mathrm{D})$ & $2.6(\mathrm{D}>\mathrm{L})$ & $1.2(\mathrm{~L}>\mathrm{D})^{\mathrm{a}}$ & $1.8(\mathrm{~L}>\mathrm{D})^{\mathrm{a}}$ \\
\hline \multicolumn{6}{|l|}{ Xan } \\
\hline & Phe & $1.1(\mathrm{D}>\mathrm{L})$ & $1.1(\mathrm{~L}>\mathrm{D})$ & 1.0 & $1.3(\mathrm{~L}>\mathrm{D})$ \\
\hline & Met & $1.1(\mathrm{D}>\mathrm{L})$ & $2.5(\mathrm{~L}>\mathrm{D})$ & $2.5(\mathrm{~L}>\mathrm{D})$ & $2.0(\mathrm{~L}>\mathrm{D})$ \\
\hline & His & $1.3(\mathrm{D}>\mathrm{L})$ & $1.3(\mathrm{D}>\mathrm{L})$ & $2.5(\mathrm{~L}>\mathrm{D})$ & $2.4(\mathrm{~L}>\mathrm{D})$ \\
\hline \multicolumn{6}{|l|}{ Aq } \\
\hline & Phe & $1.5(\mathrm{~L}>\mathrm{D})$ & $2.8(\mathrm{~L}>\mathrm{D})$ & $1.3(\mathrm{~L}>\mathrm{D})$ & $1.6(\mathrm{~L}>\mathrm{D})$ \\
\hline & Met & $5.6(\mathrm{D}>\mathrm{L})$ & $1.8(\mathrm{~L}>\mathrm{D})$ & $1.2(\mathrm{~L}>\mathrm{D})$ & $1.2(\mathrm{D}>\mathrm{L})$ \\
\hline & His & $2.1(\mathrm{~L}>\mathrm{D})$ & $2.4(\mathrm{D}>\mathrm{L})$ & $1.2(\mathrm{~L}>\mathrm{D})$ & $1.3(\mathrm{D}>\mathrm{L})$ \\
\hline
\end{tabular}

\footnotetext{
${ }^{\mathrm{a}}$ See Ref. 14.
} 
Table 4. Experimental conditions

\begin{tabular}{|c|c|c|c|c|c|c|}
\hline Guest & $C_{\text {guest }}(\mathrm{M})$ & $\lambda_{\mathrm{ex}}(\mathrm{nm})$ & $\Delta \lambda_{\mathrm{em}}(\mathrm{nm})^{\mathrm{a}}$ & Solvent $^{\mathrm{a}}$ & Ex. slit (nm) & Em. slit (nm) \\
\hline Py & $2 \times 10^{-7}$ & 337 & $360: 450$ & $\mathrm{MeOH}$ & 1.5 & 1.5 \\
\hline $\mathbf{A q}^{\mathrm{b}}$ & $2 \times 10^{-6}$ & 310 & $320: 450$ & Diox & 5 & 5 \\
\hline $\mathbf{A q}^{\mathrm{c}}$ & $2 \times 10^{-6}$ & 310 & $320: 450$ & Diox & 3 & 5 \\
\hline Xan & $4 \times 10^{-6}$ & 348 & $360: 450$ & $\mathrm{MeOH}$ & 1.5 & 3 \\
\hline
\end{tabular}

See Section 3.2.

${ }^{\mathrm{b}}$ In the presence of $\beta-C D$.

${ }^{\mathrm{c}}$ In the presence of am- $\beta-C D$.

to $\mathbf{X a n}(\mathbf{P y}>\mathbf{A q}>\mathbf{X a n})$, underlining that the best chiral selector is the complex having the most hydrophobic guest. This result perfectly agrees with Alexander et al. ${ }^{22}$ who observed that chiral recognition ability of cyclic receptors depends on the number of included water molecules that had been excluded by the chiral molecule.

Chiral recognition ability is also influenced by the binary complex symmetry. In fact, the complexes formed by $\mathbf{P y}$ and Aq show higher enantioselectivity than those formed by Xan as a consequence of their symmetry. This seems to confirm that, in the presence of binary complex, the ability to interact with a chiral molecule depends on the extension of the empty volume of the cyclodextrin cavity. This result agrees with Buvári-Bacza et al. $^{23}$ who determined that cyclodextrins having a different number of substituents and, consequently, different size cavities have different chiral discrimination ability.

Chiral recognition ability is not dependent on the effect (stabilization or destabilization) of ternary agent addition, as can be seen from data relative to $\mathbf{P y} / \beta-\mathrm{CD} / \mathbf{P h e}$ and $\mathbf{P y} /$ am- $\beta-\mathrm{CD} / \mathrm{Met}$ at $\mathrm{pH}=8.0$. Differently from that previously reported by Inoue et al. ${ }^{24}$ who observed a loss of chiral recognition with the enhancement in complex stability. In our opinion, the disagreement comes from the difference in substrate-CD interaction and substrate-binary complex interaction. Indeed, the former leads to the best host-guest fit, whereas the latter should consist of an optimal arrangement of components of ternary complex.

In conclusion the binary complexes studied seem to be promising chiral selectors able to discriminate very dilute solution of enantiomers. In many cases, the enantioselectivity ratios, determined by us, are comparable or higher than those previously reported using other molecular receptors for amino acids. On this subject Escuder et al., studying the chiral recognition ability of some amino acid appended diphenylglycoluril based receptors, found a L-enantioselectivity, in the presence of Phe, equal to 2.2. Furthermore, considering binary complexes formed by functionalized $\beta$-cyclodextrins, in the presence of $\mathrm{Cu}^{2+}$, Corradini et al. ${ }^{10 \mathrm{e}}$ reported L-enantioselectivity, in the presence of Phe, that ranged from 1.12 up to 5.26. In our case, the L-enantioselectivity for Phe ranges from 1.0 up to 7.4 .

\section{Experimental}

\subsection{Materials}

The heptakis-(6-amino-6-deoxy)- $\beta$-cyclodextrin was synthesized and purified according to the procedure described in the literature. ${ }^{25}$ The product was dried for $24 \mathrm{~h}$ in a dryer under vacuum over phosphorous pentoxide at $60{ }^{\circ} \mathrm{C}$ and then was stored in the same apparatus at $40^{\circ} \mathrm{C}$.

Py, Aq and Xan (spectrofluorimetric grade) were purchased from Fluka and used without further purification.

All amino acids were purchased from Aldrich and used without further purification.

Borate buffer solutions $(0.05 \mathrm{M})$ were prepared according to standard procedure, using freshly double-distilled decarbonised water. The actual $\mathrm{pH}$ of the solutions was recorded using a PH M82 Radiometer equipped with a GK2401C combined electrode.

\subsection{Spectrometric measurements}

The solution of $\beta-C D$ or am- $\beta-C D$ in borate buffer $(1.4 \times$ $10^{-3} \mathrm{M}$ ) was filtered before use by a Millipore $0.45 \mu \mathrm{m}$ filter. Guests solutions were prepared by injecting a guest solution (MeOH or 1,4-dioxane) $\left(\sim 10^{-3} \mathrm{M}\right)$ into a buffer solution. Measurement solutions were prepared by adding increasing volumes of the $\mathrm{CD}$ to $1 \mathrm{~mL}$ of the guest and ternary agent solution into a volumetric flask. In these solutions, the concentrations of the guest and the ternary agent were constant. The concentration of ternary agent was equal to $1 \times 10^{-3} \mathrm{M}$, while the concentration of $\mathrm{CD}$ increased from $1.4 \times 10^{-4} \mathrm{M}$ to $1.3 \times 10^{-3} \mathrm{M}$. All measurement solutions were deareated, before use, by Ar for $12 \mathrm{~min}$. The concentration of guests and the experimental condition are reported in Table 4.

Steady-state fluorescence spectra were acquired with a JASCO FP-777W spectrofluorimeter. Excitation, emission slits, excitation wavelength $\left(\lambda_{\mathrm{ex}}\right)$ and emission interval $\left(\Delta \lambda_{\mathrm{em}}\right)$ are reported in Table 4 .

Every spectrum was averaged over 50 scans. A suitable wavelength was chosen after recording a difference spectrum by comparison to a sample without cyclodextrin and one with the highest cyclodextrin concentration.

\section{Acknowledgements}

Financial support from the University of Palermo (funds for selected topics) and Italian MIUR within National Project 'Non-aromatic heterocyclic in stereo-controlled processes' is gratefully acknowledged. 


\section{References and notes}

1. Ogston, A. G. Nature (London) 1948, 162, 963.

2. Cramer, F. The Lock and Key Principle; Behr, J.-P., Ed.; 1994, 1-23. Chichester.

3. Davankov, V. A. Chirality 1997, 9, 99-102.

4. (a) Peczuh, M. A.; Hamilton, A. D. Chem. Rev. 2000, 100, 2479-2494. (b) Irie, T.; Uekama, K. Adv. Drug Deliv. Rev. 1999, 36, 101-123.

5. (a) Cram, D. J. Science 1988, 240, 760-767. (b) Cram, D. J. Angew. Chem., Int. Ed. Engl. 1988, 27, 1009-1020. (c) Stoddart, J. F. Chem. Soc. Rev. 1979, 8, 85-142. (d) Bradshaw, J. S.; Huszthy, P.; Mc Daniel, C. W.; Oue, M.; Zhu, C. Y.; Izatt, R. M. J. Coord. Chem. 1992, 27, 105-114. (e) Yokota, K.; Haba, O.; Satoh, T. Macromol. Chem. Phys. 1995, 196, 2383-2416.

6. (a) Cram, D. J.; Hegelson, R. C.; Sousa, L. R.; Timko, J. M.; Newcomb, M.; Moreau, P.; de Jong, F.; Gokel, G. W.; Hoffmann, D. H.; Domeir, L. A.; Peacock, S. C.; Madan, K.; Kaplan, L. Pure Appl. Chem. 1975, 43, 327-349. (b) Cram, D. J. J. Incl. Phenom. 1988, 6, 397-413.

7. Escuder, B.; Rowan, A. E.; Feiters, M. C.; Nolte, R. J. M. Tetrahedron 2004, 60, 291-300.

8. (a) Rekharsky, M. V.; Schwarz, F. P.; Tewari, Y. B.; Goldberg, R. N. J. Phys. Chem. 1994, 98, 10282-10288. (b) Hembury, G.; Rekharsky, M.; Nakamura, A.; Inoue, Y. Org. Lett. 2000, 2, 3257-3260.

9. (a) Mwakibete, H.; Bloor, D. M.; Wyn-Jones, E. J. Incl. Phenom. Mol. Recognit. Chem. 1991, 10, 497-505. (b) Maletic, M.; Wennemers, H.; McDonald, D. Q.; Breslow, R.; Still, W. C. Angew. Chem. 1996, 108, 1594-1596. (c) Hacket, F.; Simova, S.; Schneider, H.-J. J. Phys. Org. Chem. 2001, 14, 159-170.

10. (a) Corradini, R.; Dossena, A.; Impellizzeri, G.; Maccarrone, G.; Marchelli, R.; Rizzarelli, E.; Sartor, G.; Vecchio, G. J. Am. Chem. Soc. 1994, 116, 10267-10274. (b) Bonomo, R. P.;
Pedotti, S.; Vecchio, G.; Rizzarelli, E. Inorg. Chem. 1996, 35, 6873-6877. (c) Bonomo, R. P.; Cucinotta, V.; Maccarrone, G.; Rizzarelli, G.; Vecchio, G. J. Chem. Soc. Dalton Trans. 2001, 1366-1373. (d) Corradini, R.; Paganizzi, C.; Marchelli, R.; Pagliari, S.; Sforza, S.; Dossena, A.; Galaverna, G.; Duchateau, A. Chirality 2003, 15, S30-S39. (e) Pagliari, S.; Corradini, R.; Galaverna, G.; Sforza, S.; Dossena, A.; Montalti, M.; Prodi, L.; Zaccheroni, N.; Marchelli, R. Chem. Eur. J. 2004, 2749-2758.

11. Liu, Y.; You, C.-C.; Zhang, H.-Y.; Zhao, Y.-L. Eur. J. Org. Chem. 2003, 1415-1422.

12. Janata, J. Anal. Chem. 1992, 64, 33R-44R.

13. Yang, H.; Bohne, C. J. Photochem. Photobiol. A 1995, 86, 209.

14. D’Anna, F.; Riela, S.; Gruttadauria, M.; Lo Meo, P.; Noto, R. Tetrahedron: Asymmetry 2002, 13, 1755-1760.

15. D'Anna, F.; Riela, S.; Lo Meo, P.; Noto, R. Tetrahedron 2004, 60, 5309-5314.

16. Job, P. Ann. Chim. 1928, 9, 113-203.

17. Xu, W.; Demas, J. N.; DeGraff, B. A.; Whaley, M. J. Phys. Chem. 1993, 97, 6546-6554.

18. (a) Scaiano, J. C. J. Am. Chem. Soc. 1980, 102, 7747-7753. (b) Barra, M.; Bohne, C.; Scaiano, J. C. J. Am. Chem. Soc. 1990, 112, 8075-8079.

19. Yang, H.; Bohne, C. J. Phys. Chem. 1996, 100, 14533-14539.

20. Liao, Y.; Bohne, C. J. Phys. Chem. 1996, 100, 734-743.

21. Muñoz de la Peña, A.; Ndou, T. T.; Zung, J. B.; Greene, K. L.; Live, D. H.; Warner, I. M. J. Am. Chem. Soc. 1991, 113, 1572-1577.

22. Alexander, J. M.; Clark, J. L.; Brett, T. J.; Stezowsky, J. Proc. Natl. Acad. Sci. U. S. A. 2002, 99, 5115-5120.

23. Buvári-Bacza, A.; Bacza, L. Talanta 1999, 49, 577-585.

24. Rekharsky, M. V.; Inoue, Y. J. Am. Chem. Soc. 2002, 124, 813-826.

25. Ashton, P. R.; Koniger, R.; Stoddart, J. F. J. Org. Chem. 1996, 61, 903-908. 